\title{
On the reversibility of transitions between closed and open cellular convection
}

\author{
G. Feingold ${ }^{1}$, I. Koren ${ }^{2}$, T. Yamaguchi ${ }^{3,1}$, and J. Kazil ${ }^{3,1}$ \\ ${ }^{1}$ Chemical Sciences Division, NOAA Earth System Research Laboratory (ESRL), Boulder, Colorado, USA \\ ${ }^{2}$ Weizmann Institute, Rehovot, Israel \\ ${ }^{3}$ Cooperative Institute for Research in Environmental Sciences, University of Colorado Boulder, Boulder, Colorado, USA
}

Correspondence to: G. Feingold (graham.feingold@ noaa.gov)

Received: 07 February 2015 - Published in Atmos. Chem. Phys. Discuss.: 26 February 2015

Revised: 04 June 2015 - Accepted: 17 June 2015 - Published: 08 July 2015

\begin{abstract}
The two-way transition between closed and open cellular convection is addressed in an idealized cloudresolving modeling framework. A series of cloud-resolving simulations shows that the transition between closed and open cellular states is asymmetrical and characterized by a rapid ("runaway") transition from the closed- to the opencell state but slower recovery to the closed-cell state. Given that precipitation initiates the closed-open cell transition and that the recovery requires a suppression of the precipitation, we apply an ad hoc time-varying drop concentration to initiate and suppress precipitation. We show that the asymmetry in the two-way transition occurs even for very rapid drop concentration replenishment. The primary barrier to recovery is the loss in turbulence kinetic energy (TKE) associated with the loss in cloud water (and associated radiative cooling) and the vertical stratification of the boundary layer during the open-cell period. In transitioning from the open to the closed state, the system faces the task of replenishing cloud water fast enough to counter precipitation losses, such that it can generate radiative cooling and TKE. It is hampered by a stable layer below cloud base that has to be overcome before water vapor can be transported more efficiently into the cloud layer. Recovery to the closed-cell state is slower when radiative cooling is inefficient such as in the presence of free tropospheric clouds or after sunrise, when it is hampered by the absorption of shortwave radiation. Tests suggest that recovery to the closed-cell state is faster when the drizzle is smaller in amount and of shorter duration, i.e., when the precipitation causes less boundary layer stratification. Cloudresolving model results on recovery rates are supported by simulations with a simple predator-prey dynamical system
\end{abstract}

analogue. It is suggested that the observed closing of open cells by ship effluent likely occurs when aerosol intrusions are large, when contact comes prior to the heaviest drizzle in the early morning hours, and when the free troposphere is cloud free.

\section{Introduction}

Satellite imagery of cloud fields over the eastern edges of the oceanic basins exhibits both closed and open cellular cloud patterns that have captured the imagination of the atmospheric scientist and the layperson alike. Interest in these cellular cloud modes has been spurred by both the desire to understand these states and to evaluate their consequences for shallow cloud reflectance and climate forcing. The closed cellular state is a mostly cloudy state characterized by broad, weak updrafts in the opaque cloudy cell center and stronger, narrower downdrafts around the cell edges. The open-cell state is the "polar opposite" or "negative" in which narrow, strong, cloudy updrafts surround broad, weak downdrafts in the optically thin cell center. These states have been studied through observation (Sharon et al., 2006; Stevens et al., 2005; Wood and Hartmann, 2006; Wood et al., 2011) and modeling (Savic-Jovcic and Stevens, 2008; Xue et al., 2008; Wang and Feingold, 2009a, b; Kazil et al., 2011, 2014; Yamaguchi and Feingold, 2015), with most efforts addressing the closedto-open cell transition. These studies have shown that rain is the likely initiator of the closed-to-open cell transition, pointing to the importance of deepening of the cloud (Mechem et al., 2012) and/or reduction in the cloud condensation nu- 
cleus concentration. An interesting aspect of the precipitating open cellular system is that strongly buoyant cloudy cells produce rain, which imposes local negative buoyancy perturbations. The cloud-rain cycles thus create an adaptive opencell state that constantly rearranges itself as clouds move through positive buoyancy (non-precipitating) and negative buoyancy (precipitating) cycles (Feingold et al., 2010; Koren and Feingold, 2013). The closed-cell state has, in contrast, a more rigid structure that maintains itself over many hours (Koren and Feingold, 2013).

A relatively under-studied aspect of the system is the twoway transition from closed-to-open-to-closed cells, which will be the focus of the current work. The results pertain to what have been termed "pockets of open cells" (Stevens et al., 2005) or rifts (Sharon et al., 2006) in which open cells periodically appear within a meteorological setting that promotes closed cellular convection. This work does not address the broader question of closed to open-cell transitions due to a warming sea surface temperature as one moves westward from the stratocumulus-capped continental coastlines. While some modeling work has addressed the two-way transition between states (Wang and Feingold, 2009b; Berner et al., 2013) and there exists ample visual evidence of ship tracks "filling in" cloudiness in open-cell fields (e.g., Goren and Rosenfeld, 2012), there remain open questions regarding the relative ease of the two transitions and the extent to which aerosol intrusions control this transition. For example, Wang and Feingold (2009b) perturbed a cloud-resolving simulation of the open-cell state with a very large aerosol perturbation, and while a thin layer of cloud did fill the open cells, the aerosol was unable to convert the system to a closed state, presumably because the cloud was too thin to generate sufficient radiative cooling. The juxtaposition of these simulations and the observations suggests that differences in meteorological conditions, aerosol perturbations, and the timing within the diurnal cycle might matter (Wang et al., 2011). The latter study explored other important factors such as the amount and distribution of the aerosol perturbation (in the form of ship tracks).

To address this problem, we use a cloud-resolving atmospheric model that uses a simple microphysical scheme with an ad hoc control over the drop concentration and therefore, all else equal, the rain production. This is in contrast to our earlier work (Kazil et al., 2011), in which the aerosol life cycle was simulated from new particle formation through wet scavenging, and to more recent two-dimensional, multi-day simulations of closed and open-cell systems (Berner et al., 2013). The choice of a simple control over drop concentration avoids a more direct assessment of the importance of the rates of aerosol removal and replenishment. Supporting simulations are also performed using a dynamical systems analogue to the aerosol-cloud-precipitation system in the form of modified predator-prey coupled equations (Koren and Feingold, 2011; Feingold and Koren, 2013; Jiang and
Wang, 2014), which provides insight into the essence of the system at minimal computational cost.

\section{Model description}

\subsection{Cloud-system resolving model (CRM)}

We use the System for Atmospheric Modeling (SAM) as described in Khairoutdinov and Randall (2003) with a secondorder centered scheme for momentum advection and a monotonic fifth-order scheme for scalar advection (Yamaguchi et al., 2011). SAM solves the anelastic Navier-Stokes equations on an Eulerian spatial grid. Prognostic equations are solved for liquid water static energy, mixing ratios of water vapor, cloud water, rain water, and subgrid-scale turbulence kinetic energy (TKE). While our earlier work used bin, or bin-emulating physics in large eddy simulation and CRM (e.g., Feingold et al., 1996; Wang and Feingold, 2009a, b), the Khairoutdinov and Kogan (2000) microphysics is chosen here for expediency and because its level of complexity is commensurate with the ad hoc specification of $N(t)$.

The initial and boundary conditions not only follow the Second Dynamics and Chemistry of Marine Stratocumulus (DYCOMS-II RF02; Ackerman et al., 2009) but also include a number of perturbations. The domain is $40 \mathrm{~km} \times 40 \mathrm{~km}$ wide and $1.6 \mathrm{~km}$ deep with a grid spacing of $200 \mathrm{~m}$ in the horizontal and $10 \mathrm{~m}$ in the vertical. Tests with finer horizontal grid spacings ( 100 and $75 \mathrm{~m}$ ) show that the key results are remarkably robust to the model grid spacing (Appendix A). The lateral boundary conditions are doubly periodic and the time step is $1 \mathrm{~s}$. Our base case is the standard Global Energy and Water Cycle Experiment (GEWEX) Cloud System Study (GCSS) DYCOMS-II RF02 case with horizontal winds $(u$; $v=7.3 ;-3.5 \mathrm{~m} \mathrm{~s}^{-1}$ at $1000 \mathrm{~m}$; see Ackerman et al., 2009) and an interactive surface model based on similarity theory; the large-scale subsidence is computed based on the largescale horizontal wind divergence of $3.75 \times 10^{-6} \mathrm{~s}^{-1}$; longwave radiative flux divergence is calculated using either a simple liquid water path-dependent method (Ackerman et al., 2009) or the coupled rapid radiative transfer model (RRTM; Mlawer et al., 1997). Because of the shallow depth of the domain, a free tropospheric sounding is patched above the domain top for the RRTM radiation calculations. For the above-domain temperature sounding, we follow Cavallo et al. (2010). The domain top value of water vapor mixing ratio is used as the above-domain water vapor profile. Different domain-top values of water vapor mixing ratio will be considered in Sect. 4.2. While in principle, the simple long-wave radiation scheme could be tuned to mimic that of RRTM (e.g., Larson et al., 2007), we have not done so. This has the salutary effect of providing different responses of radiative cooling to liquid water path, which will serve to elucidate sensitivity of transitions to long-wave radiative cooling. 
Simulations are on the order of $18 \mathrm{~h}$ so that some include significant periods of shortwave radiation. Perturbations to these initial and boundary conditions are shown in Sect. 3.1.4.

\subsection{Predator-prey model}

The second model is an adaptation of the the predator-prey model (Koren and Feingold, 2011). The model comprises three equations that describe the cloud depth $H$, drop concentration $N$, and rain rate $R$ for the cloud system:

$$
\begin{aligned}
\frac{\mathrm{d} H}{\mathrm{~d} t} & =\frac{H_{0}-H}{\tau_{1}}-\frac{\alpha H^{2}(t-T)}{c_{1} N(t-T)}, \\
\frac{\mathrm{d} N}{\mathrm{~d} t} & =\frac{N_{0}-N}{\tau_{2}}-c_{2} N(t-T) R \text { and } \\
R(t) & =\frac{\alpha H^{3}(t-T)}{N(t-T)},
\end{aligned}
$$

where $c_{1}$ is a temperature-dependent constant, and $c_{2}$ and $\alpha$ are constants based on theory. $H_{0}$ is the cloud depth that would be reached within a few timescales $\tau_{1}$ in the absence of rain-related losses. Thus $H_{0}$ represents "meteorological forcing" or, in population dynamics nomenclature, the "carrying-capacity" of the system. Similarly, $N_{0}$ is the drop (or aerosol) concentration "carrying-capacity" that the system would reach in a few $\tau_{2}$ in the absence of rain. The $N$ loss term on the right-hand side of Eq. (2) captures a physically based rate of removal. The delay $T$ represents the time required for cloud water to be converted to rainwater by collision and coalescence between drops and introduces significant complexity and nuanced response in the system of equations (Feingold and Koren, 2013). Here we substitute Eq. (2) with a simple time-varying $N$ similar to that imposed in the CRM simulations. Rain rate is diagnosed from the prognostic variables $H$ and $N$, again with delay $T$ (Eq. 3). While the system of Eqs. (1)-(3) is represented by five primary parameters, $H_{0}, N_{0}, \tau_{1}, \tau_{2}$, and $T$, the use of a prescribed $N(t)$ instead of Eq. (2) reduces the free parameters to $H_{0}, \tau_{1}$, and $T$. In the current work, we will select values of these parameters that are physically plausible and/or that help illustrate the key points.

\section{Results}

\subsection{Cloud-resolving modeling}

\subsubsection{Time variation in $N$}

A series of simulations with a prescribed evolution of drop concentration $N$ is applied to all simulations (Fig. 1). The time series starts with a steady $N=90 \mathrm{mg}^{-1}$ (equivalent to $90 \mathrm{~cm}^{-3}$ at an air density of $1 \mathrm{~kg} \mathrm{~m}^{-3}$ ), which for the current case generates closed-cell conditions with minimal precipitation. It then mimics the rapid drop in $N$ associated with the

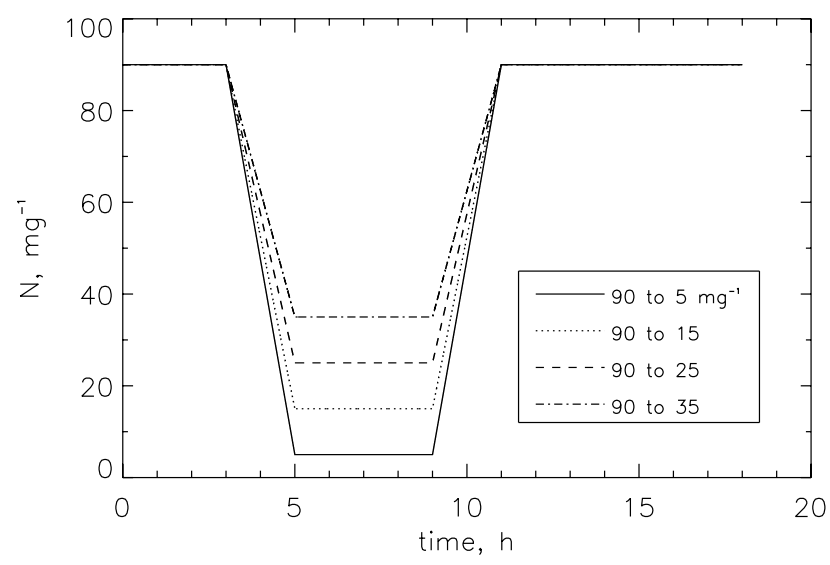

Figure 1. Imposed time series of drop concentration $N$. The minimum $N$ is varied between 5 and $35 \mathrm{mg}^{-1}$.

runaway reduction in $N$ in a developing open cell over the course of $2 \mathrm{~h}$ (e.g., Feingold et al., 1996; Wang and Feingold, 2009a); a 4 h period of steady, low $N$; and then an equally rapid ( $2 \mathrm{~h}$ ) rise in $N$ back to pre-open-cell conditions. Four different values of low $N$ are applied: 5, 15, 25, and $35 \mathrm{mg}^{-1}$. The rapid rise back to $90 \mathrm{mg}^{-1}$ is unrealistic given earlier work that estimated a recovery time of $\sim 10 \mathrm{~h}$ (Berner et al., 2013) but, as will be shown, it provides a (near) upper bound on replenishment of the drop concentration, and anything less rapid serves to strengthen the arguments to be presented. The time series of $N$, specifically the recovery to $N=90 \mathrm{mg}^{-1}$, will be varied in a number of sensitivity tests.

\subsubsection{Control Simulations}

The control simulations use the GCSS specifications as described above, the simple long-wave radiation scheme (no shortwave radiation) and surface latent and sensible heat fluxes that respond to the local surface horizontal winds. A series of snapshots of the cloud liquid water path (LWP) calculated from the modeled cloud and rain water mixing ratios (Fig. 2) shows an initial closed cellular state transitioning to an open-cell state (distorted by the mean northwesterly flow), a filling in of cloud associated with the increase in $N$, which gradually provides colloidal and dynamical stability to the cloud and, finally, a more complete closed cellular cloud cover.

Figure 3 shows time series of the domain mean cloud LWP, rain water path (RWP), surface rain rate $R_{\text {sfc }}$, and the mean surface rain rate conditionally sampled for $R_{\text {sfc }} \geq 0.1 \mathrm{~mm} \mathrm{~d}^{-1}$ ( $\left.R_{\text {cond }}\right)$. After the "spin up" of turbulence, by $t=3 \mathrm{~h}$ the LWP is approximately steady at $110 \mathrm{~g} \mathrm{~m}^{-2}$ (although decreasing slowly). The reduction in $N$ after $3 \mathrm{~h}$ results in rapid reduction in domain average LWP as rain ensues and cloud cover decreases, a period of relatively steady LWP - particularly for the low minimum $N$ - and then a slow recovery after the increase in $N$ at $t=9 \mathrm{~h}$. In spite of 

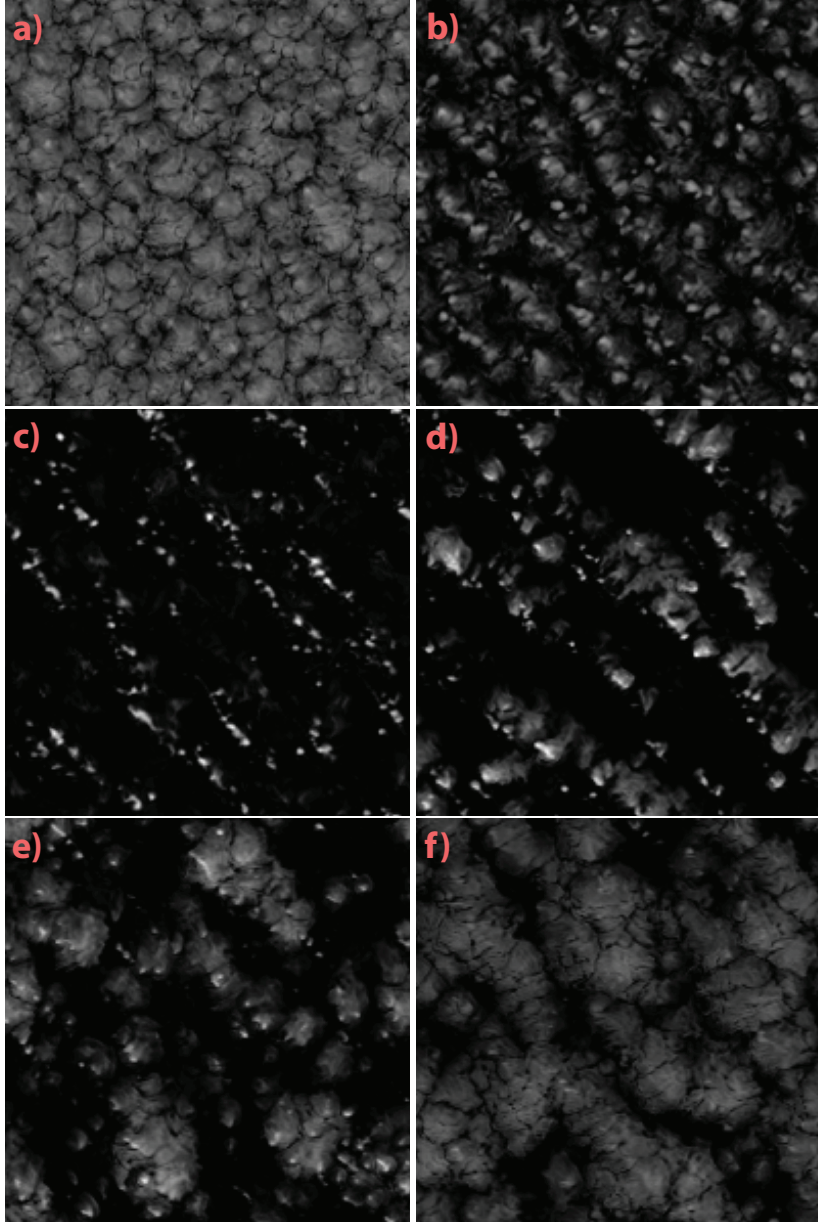

Figure 2. LWP at $t=$ (a) $3 \mathrm{~h}$ (closed cell), (b) $5 \mathrm{~h}$ (closed transitioning to open), (c) $7 \mathrm{~h}$ (open cell), (d) $11 \mathrm{~h}$ (open transitioning to closed), (e) $13 \mathrm{~h}$ (further recovery to closed), (f) $18 \mathrm{~h}$ (closed cell). Control simulation with minimum $N=5 \mathrm{mg}^{-1}$. The grey scale ranges from 0 to $450 \mathrm{~g} \mathrm{~m}^{-2}$.

the symmetry in the ramping down and up of $N$, there exists an asymmetry in $\operatorname{LWP}(t)$ commensurate with the minimum imposed value of $N$. Asymmetry also exists in $\operatorname{RWP}(t)$; initially strong RWP during the onset of drizzle $(t \approx 5 \mathrm{~h})$ is followed by a more steady but lower RWP $(t=6-9 \mathrm{~h})$ and relatively steady $R_{\text {sfc }}$. This period is characterized by a balance between dynamical forcing that replenishes cloud liquid water and by drizzle losses. Note that the start of the increase in $N$ at 9 h does not put an immediate stop to rain, as evidenced by the long tail of low RWP and $R_{\mathrm{sfc}}$ that persists even after $N=90 \mathrm{mg}^{-1}(t=11 \mathrm{~h})$. This is because in these very clean conditions the increase in $N$ initially helps to boost LWP, which further boosts rain. (Recall that $R \propto \mathrm{LWP}^{\alpha} N^{-\beta}$; e.g., Pawlowska and Brenguier, 2003, with $\alpha$ approximately $3 \times$ larger than $\beta$.)

Figure 4 shows the mean cloud fraction $f_{\mathrm{c}}$ (defined by a cloud liquid water mixing ratio $q_{\mathrm{c}}$ threshold of $\left.0.01 \mathrm{~g} \mathrm{~kg}^{-1}\right)$, surface latent heat $(\mathrm{LH})$ and sensible heat $(\mathrm{SH})$ fluxes, in-
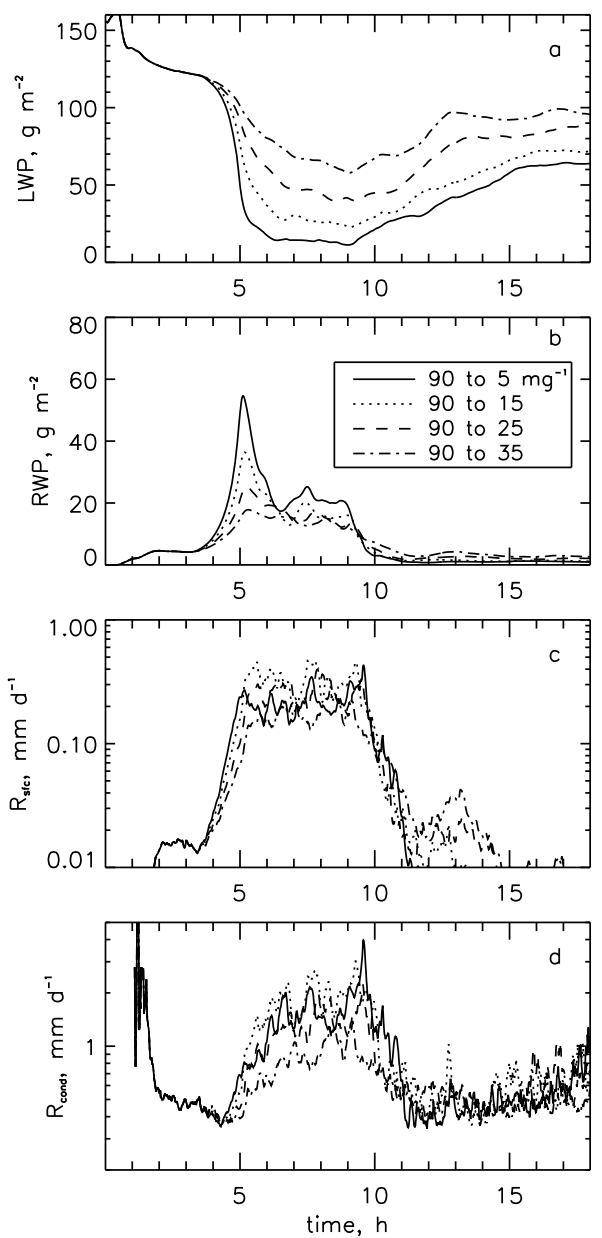

Figure 3. Time series of (a) LWP, (b) rain water path (RWP), (c) domain mean surface rain rate $R_{\mathrm{sfc}}$, and (d) surface rain rate conditionally sampled for $R \geq 0.1 \mathrm{~mm} \mathrm{~d}^{-1}$ ( $R_{\text {cond }}$ ) for the control case and for the various minimum $N$ as in Fig. 1. Recovery becomes progressively more difficult with decreasing minimum $N$. The initial spike in surface $R_{\text {cond }}$ is related to the fact that during the first hour of simulation, collision-coalescence and sedimentation are not simulated.

version height $z_{\mathrm{i}}$ (based on the maximum gradient in liquid water potential temperature $\theta_{1}$ ), and cloud base/top height $\left(z_{\mathrm{b}} / z_{\mathrm{t}}\right.$; calculated based on a $q_{\mathrm{c}}$ threshold of $\left.0.01 \mathrm{~g} \mathrm{~kg}^{-1}\right)$. $\left(\theta_{1} \approx \theta-q_{\mathrm{c}} L_{\mathrm{v}} / c_{\mathrm{pd}}\right.$; with $L_{\mathrm{v}}$ the latent heat of vaporization and $c_{\mathrm{pd}}$ the specific heat of dry air at constant pressure.) Cloud fraction recovery is approximately symmetrical for high minimum $N$ but becomes increasingly more asymmetrical as the minimum $N$ approaches $5 \mathrm{mg}^{-1}$. Surface latent heat fluxes decrease, while sensible heat fluxes increase during the open-cell period, consistent with the cooler and moister surface outflows (see e.g., Kazil et al., 2014, for more detailed analysis of the surface flux responses). The preopen-cell rise in cloud base and top height is suppressed during the raining period. Cloud bases for the different $N$ perturbations all tend to converge after full recovery of $N$, while 

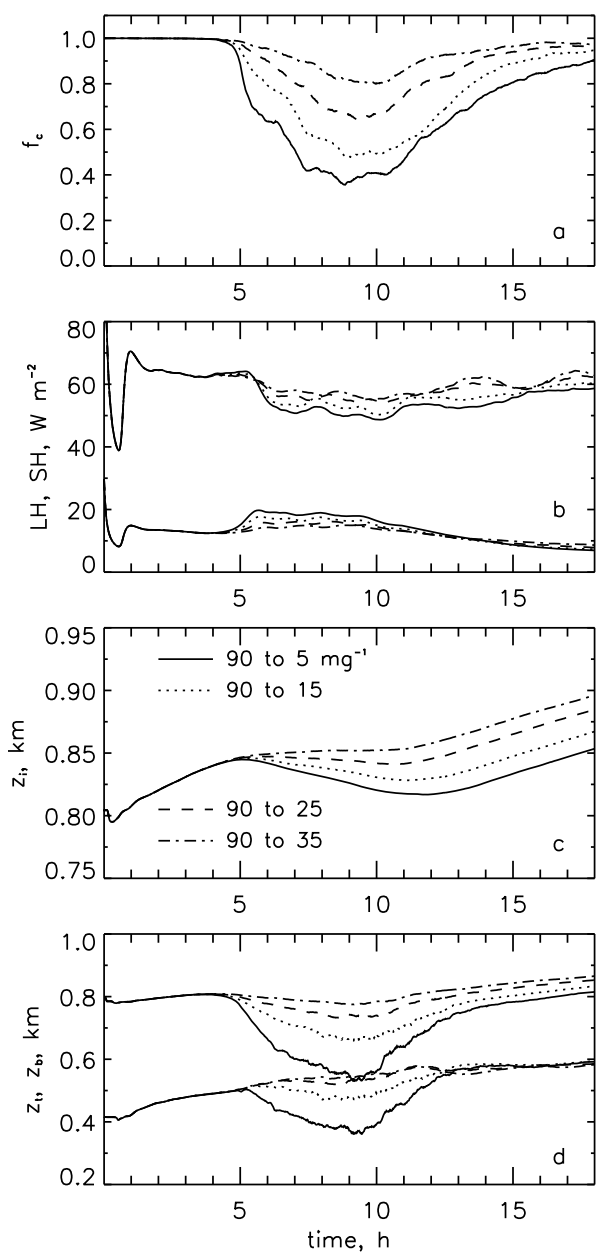

Figure 4. Time series of (a) cloud fraction $f_{\mathrm{c}}$, (b) surface latent and sensible heat fluxes ( $\mathrm{LH}$ and $\mathrm{SH}$, respectively; $\mathrm{LH}>\mathrm{SH}$ ), (c) inversion height $z_{\mathrm{i}}$, and (d) cloud top $z_{\mathrm{t}}$ and cloud base $z_{\mathrm{b}}$ for the control case and the various minimum $N$ as in Fig. 1. Note the suppression of the deepening of the boundary layer associated with drizzle.

cloud tops for the stronger perturbations are up to $\sim 50 \mathrm{~m}$ lower. Note that because the calculations of $z_{\mathrm{t}}$ and $z_{\mathrm{i}}$ apply different criteria, the absolute values are somewhat different. The main point, however, is to compare the response to different $N(t)$.

\subsubsection{No aerosol perturbation}

It is of interest to compare these perturbed simulations to one in which there is no perturbation to $N$, i.e., $N=90 \mathrm{mg}^{-1}$ for the entire simulation. Figure 5 shows profiles of total liquid water, total water mixing ratio $q_{\mathrm{t}}$, and $\theta_{\mathrm{l}}$ for the control case and a simulation without any $N$ perturbation. In the absence of a perturbation to $N$, the cloud does not produce substantial drizzle; even though the boundary layer deepens steadily, it does not produce enough liquid water to generate precipitation at $N=90 \mathrm{mg}^{-1}$, and it remains reasonably well mixed. In contrast, the control simulation with a strong perturbation to $N\left(5 \mathrm{mg}^{-1}\right)$ exhibits significant drizzle-related reduction in cloud water and significant perturbation to the well-mixed state (Fig. 5, left column). Notably, and in agreement with earlier studies (e.g., Stevens et al., 2005), the cloud layer dries and thus warms during the precipitating period while the surface cools and moistens. For example, this can be deduced from the fact that $\theta_{1}$ is steady while $q_{\mathrm{c}}$ decreases, which means that $\theta$ must have increased. By the end of the simulation, vertical mixing has increased; $\theta_{1}$ is approximately constant with height. For $q_{\mathrm{t}}$, vertical mixing also increases although a moister layer exists up to a depth of $100 \mathrm{~m}$. Overall, however, the morphological structure of the cloud field, its flow structure (not shown) and the thermodynamic profiles at the end of the simulation, are consistent with a closed cellular system.

\subsubsection{Sensitivity tests}

A number of sensitivity tests and perturbations to the initial and boundary conditions were performed to gauge robustness in the response to the $N(t)$ perturbation. These include (i) fixed surface fluxes $\left(\mathrm{SH}=15 \mathrm{~W} \mathrm{~m}^{-2}\right.$ and $\mathrm{LH}=93 \mathrm{~W} \mathrm{~m}^{-2}$ ); (ii) simulation of both shortwave and longwave radiation using RRTM; (iii) changing start times in the diurnal cycle; and (iv) varying free tropospheric humidity and large-scale subsidence. This is just a subset of the various tests that could be performed. Figure 6 shows time series plots of LWP for these various tests. In all cases the asymmetry in $\operatorname{LWP}(t)$ in response to $N(t)$ is clear. Of interest is that RRTM tends to generate stronger long-wave radiative cooling and therefore even in the presence of shortwave radiation, LWP recovery after the open-cell period is much more effective (cf. Figs. 3a and 6b; see further discussions in Sect. 4.2). Delays in the start time of the simulation slow the LWP recovery (progressively weaker slopes with increasing delay in Fig. 6c) because of shortwave absorption, but once $N$ has returned to $90 \mathrm{mg}^{-1}$ the simulations converge. Other significant changes to the simulations are in response to changes in subsidence and free tropospheric humidity (Fig. 6d). A drier free troposphere (see figure caption for details) reduces LWP during the first $4 \mathrm{~h}$ of simulation before the onset of drizzle. This reduction in LWP is magnified in the case of stronger subsidence, but in the case of weaker subsidence the loss in LWP is countered by the ability of the boundary layer to generate a deeper cloud. As might be expected, recovery to the closed-cell state is slowest in the case of a dry free troposphere in combination with strong subsidence. Thus meteorological conditions that influence cloudiness itself set the stage for the rate of recovery after the drizzling period. 



Figure 5. Domain average profiles of (a) and (b) liquid water mixing ratio $q_{\mathrm{c}}$, (c) and (d) total water mixing ratio $q_{\mathrm{t}}$, and (e) and (f) liquid water potential temperature $\theta_{1}$. Left column: control case with minimum $N=5 \mathrm{mg}^{-1}$; right column: $N=90 \mathrm{mg}^{-1}$ throughout the simulation. Drizzle results in a drying of the cloud layer and a moistening of the surface (c). The drizzling period is characterized by poor average vertical mixing. The drizzling system eventually recovers to a well-mixed state, although surface moisture persists.

\subsection{Relationship between recovery, turbulence kinetic energy, and convective available potential energy}

Stratocumulus cloud water provides a source of long-wave radiative cooling, which generates negative buoyancy and turbulence. Surface precipitation removes liquid water from the cloud layer and deposits it to the surface. Surface precipitation therefore reduces the amount of cooling associated with the evaporation of cloud water in the cloud layer and warms the cloud layer. Near-surface evaporation of precipitation cools the surface layer. Thus surface precipitation serves to stabilize the boundary layer (e.g., Stevens et al., 1998). We therefore expect rain processes to manifest in TKE and convective available potential energy (CAPE). We analyze an illustrative case that includes a diurnal cycle (start time 21:00 LT) and a cycle of $N$ from 90 to 5 to $90 \mathrm{mg}^{-1}$ (Fig. 6b solid line). TKE is the grid-resolved component averaged over the boundary layer depth. Sunrise is at approximately 06:00 LT, i.e., about the time of the beginning of $N$ recovery. A time series of LWP, TKE, and CAPE reveals that during the initial closed-cell phase (prior to $t=24 \mathrm{~h}$ ), LWP drives production of TKE (Fig. 7a, b), which in turn drives higher LWP. The prescribed drop in $N$ results in precipitation and a loss of LWP. TKE also drops but with a delay of approximately $1 \mathrm{~h}$. This delay is associated with the surge in surface TKE on transition to the open-cell state, associated with the surface outflows (Fig. 8a, $t \approx 27 \mathrm{~h}$ ). The surface TKE slowly wanes as the surface rain rate and outflows weaken. (The peak transitions back to cloud top upon recovery of the closed-cell state at $t>32 \mathrm{~h}$.) TKE continues to decrease during the open-cell drizzling phase and only begins to rebound approximately $1 \mathrm{~h}$ after the introduction of $N$ and the LWP recovery (Fig. 7b). Later, LWP and TKE increase in unison and eventually peak simultaneously at maximum cloud re- 



Figure 6. Tests of robustness of LWP recovery. (a) Control case but with fixed surface fluxes and no winds. Line types as in Fig. 1; (b) RRTM (shortwave and long wave) and start time of 21:00 LT. Line types as in Fig. 1. The arrow points to sunrise at 06:00 LT ( $t=30 \mathrm{~h})$; (c) as in (b) but with start times staggered by $1 \mathrm{~h}$ between 20:00 and 23:00 LT; (d) control case (solid line); dry air aloft (dashed line), dry air aloft and divergence increased to $5 \times 10^{-6} \mathrm{~s}^{-1}$ (dotted line), and dry air aloft but divergence decreased to $1 \times 10^{-6} \mathrm{~s}^{-1}$ (dash-dotted line). The drier air aloft is calculated according to $q_{\mathrm{v}}=q_{\mathrm{v}, 0}-3 \mathrm{~g} \mathrm{~kg}^{-1}[1-\exp ((795-z) / 500)]$ with $q_{\mathrm{v}, 0}=3 \mathrm{~g} \mathrm{~kg}^{-1}$ rather than $q_{\mathrm{v}, 0}=5 \mathrm{~g} \mathrm{~kg}^{-1}$ as in the control case. (Terms in the exponent are in meters.) The precipitable water at $t=0$ is $10.0 \mathrm{~mm}$ compared to $11.7 \mathrm{~mm}$ for the standard profile. In (c) and (d) the minimum $N=5 \mathrm{mg}^{-1}$.

covery. During the last $4 \mathrm{~h}$ of the simulation, absorption of shortwave radiation results in a decrease in LWP. There is a steady decrease in CAPE over the course of the simulation, which is also indicative of the inability of the system to rebound.

The asymmetry of the closed-open-closed transition cycle is nicely demonstrated as a plot in LWP-TKE phase space
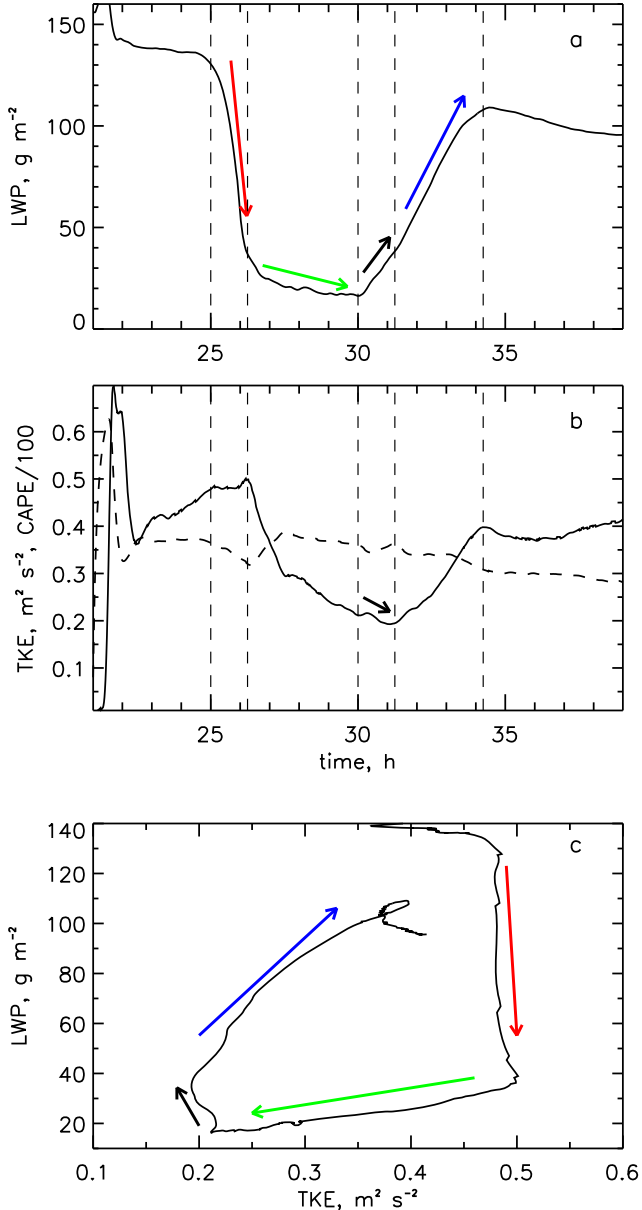

Figure 7. Analysis of RRTM simulation and minimum $N=5 \mathrm{mg}^{-1}$ (solid line, Fig. 6b). Time series of (a) domain mean LWP and (b) TKE averaged horizontally, over the boundary-layer depth (solid line), and CAPE (dashed line); (c) a phase diagram of (a) vs. (b). Colored arrows indicate stages of evolution of the system. Vertical dashed lines are included to focus on temporal phase lags between LWP and TKE. Red arrow: LWP falls rapidly while TKE continues to increase; green arrow: both LWP and TKE decrease; black arrow: LWP begins to recover while TKE still decreases; blue arrow: LWP and TKE increase in unison as the closed-cell state recovers. For $t>24 \mathrm{~h}$, subtract 24 to get local time.

(Fig. 7c). During the delay in TKE recovery upon reintroduction of $N(t=30-31 \mathrm{~h})$, turbulence does not reinforce the LWP increase. Thus LWP recovery following the introduction of $N$ is hampered by the inability of the system to generate turbulence via radiative cooling - itself a function of LWP.

Further analysis of the recovery shows that recovery is hampered by below cloud buoyancy consumption of TKE (Fig. 8b) at $t \approx 32 \mathrm{~h}$ and a height of $\approx 250 \mathrm{~m}$ (marked by a white minus sign on the figure). Analysis of other cases shows that this is a robust feature during the recovery stage, although it varies in magnitude and extent. Horizontal $x$ - 

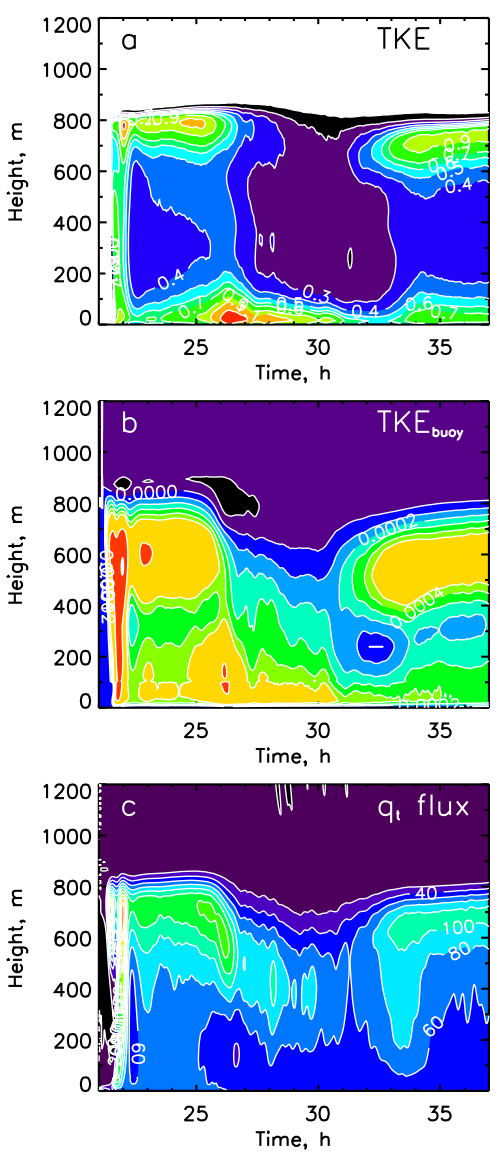

Figure 8. Time-height cross sections associated with Fig. 7: (a) resolved TKE $\left(\mathrm{m}^{2} \mathrm{~s}^{-2}\right)$, (b) buoyancy production of TKE $\left(\mathrm{m}^{2} \mathrm{~s}^{-3}\right)$, and (c) $q_{\mathrm{t}}$ flux $\left(\mathrm{W} \mathrm{m}^{-2}\right)$. Note how in (a), the peak TKE transitions from the cloud layer to the surface during closed-to-open cell transition $(t \approx 26 \mathrm{~h})$ and back to the cloud layer upon recovery. In (b), an area of negative buoyancy production of TKE (consumption) is indicated by a white minus sign $(t \approx 33 \mathrm{~h})$. After the disappearance of this region of buoyancy consumption of TKE, stronger $q_{\mathrm{t}}$ flux into the cloud is evident (panel $\mathbf{c}, t \approx 33 \mathrm{~h}$ ).

$y$ slices through this region reveal that the buoyancy consumption of TKE is related to rising of cold air and sinking of warm air (e.g., Moeng, 1987). (Figure not shown.) After the disappearance of this region of buoyancy consumption of TKE, the total water flux (vapor plus cloud water) into the cloud increases significantly (Fig. 8c, $t>33 \mathrm{~h}$ ).

\subsubsection{Influence of rate of $N$ replenishment on recovery}

Given the simplicity of the $N$ representation, it is useful to consider whether recovery is limited by the rate of recovery of $N$ at the end of the open-cell phase. Two variations on the control simulations (Figs. 1,3) are repeated. The first ramps $N$ up from 5 to $90 \mathrm{mg}^{-1}$ within $5 \mathrm{~min}$ (as opposed to $2 \mathrm{~h}$ ); the second ramps $N$ up to $300 \mathrm{mg}^{-1}$, also within $5 \mathrm{~min}$ (Fig. 9); both are highly unrealistic, considering the aerosol
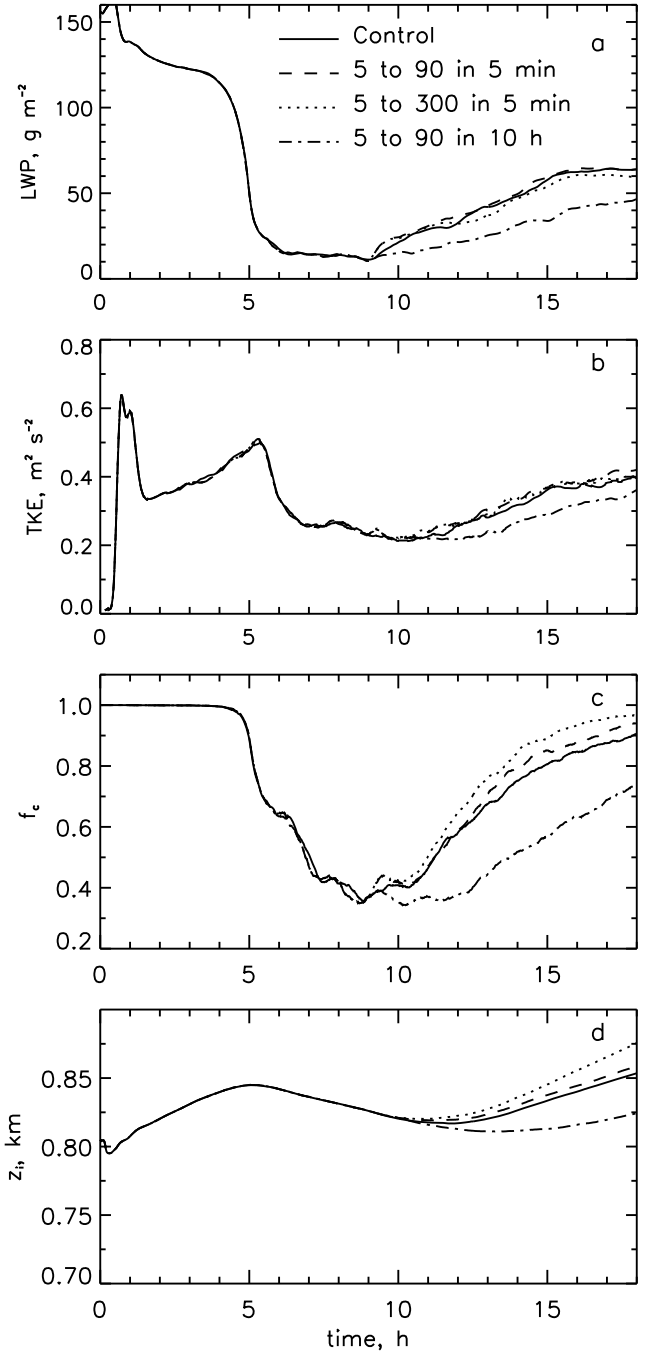

Figure 9. Simulations testing the importance of $N$ for recovery of the closed-cell state for control case set up with variations. Simulations prior to $t=9 \mathrm{~h}$ are the same (slight differences are due to different machine compilers and processors). After $t=9 \mathrm{~h}, N$ increases to $90 \mathrm{mg}^{-1}$ within $2 \mathrm{~h}$ as in Fig. 1 (solid line, control); $N$ recovers to $90 \mathrm{mg}^{-1}$ within $5 \mathrm{~min}$ (dashed line); $N$ recovers to $300 \mathrm{mg}^{-1}$ within $5 \mathrm{~min}$ (dotted line); and $N$ recovers to $90 \mathrm{mg}^{-1}$ within $10 \mathrm{~h}$ (dash-dotted line).

replenishment rates via new particle formation, mechanical surface production, and entrainment (Kazil et al., 2011). It is clear that even these unrealistically high $N$ recharge rates make little difference in terms of the rate of increase in LWP and TKE. Small enhancements in recovery in $f_{\mathrm{c}}$ and deepening of the boundary layer are, however, evident. A more realistic $N$ recovery rate of $t=10 \mathrm{~h}$ further delays recovery. Thus while the rate of replenishment of $N$ is clearly an important controlling factor for recovery, even immediate replenishment does not erase the asymmetry in the LWP and TKE recovery. 


\subsubsection{Influence of meteorological forcing on recovery}

Given the close relationship between LWP and TKE - albeit with delay - we hypothesize that an appropriately placed influx of energy and water into the system should help recovery. There are various ways that this can be explored in modeling world; one straightforward way is by increasing surface sensible and latent heat fluxes which generate surface-driven buoyancy and moisture (e.g., Xue and Feingold, 2006). Another is through stronger cloud top cooling, which is explored in Sect. 4.2. The control simulation is repeated, but this time the interactively calculated values of SH and LH are both increased by a factor of 2 , coincident with and following the beginning of the ramp up of $N$ at $9 \mathrm{~h}$. This is an ad hoc simulation and is not meant to be tied to a specific scenario. As shown in Fig. 10, recovery is significantly stronger. This simulation also exhibits a layer of buoyancy consumption of TKE centered on $\sim 300 \mathrm{~m}$ during the recovery stage $(t>10 \mathrm{~h}$ for this case), as in Fig. 8b. However it is significantly weaker and diminished in size compared to the control case with standard interactive fluxes (figures not shown). Moreover, the $q_{\mathrm{t}}$ flux into the cloud layer is stronger and starts earlier in the recovery stage than for the control case. Thus the increased $\mathrm{SH}$ and LH help to reduce the strength, extent, and duration of this layer of buoyancy consumption of TKE, thereby accelerating recovery. An additional case in which only $\mathrm{LH}$ was doubled and SH was kept the same produced similar results vis-à-vis recovery in LWP during the open-to-closed cell transition, although there was a proliferation of shallow cumulus with low cloud base during this stage resulting from the lower lifting condensation level. Meteorological forcing that generates thicker cloud appears to be important for increasing the rate of LWP and TKE recovery and transition back to the open-cell state.

\section{Discussion}

\subsection{The predator-prey model}

We explore the ability of the predator-prey model to capture key responses of the system to changes in $N$ emanating from the CRM simulations. To do so, we replace Eq. (2) with a time series much like that in Fig. 1 with high and low $N$ values of $90 \mathrm{~cm}^{-3}$ and $5,15,25$, or $35 \mathrm{~cm}^{-3}$, respectively. The transition times and the duration of the low $N$ state are the same as in Fig. 1 except the time axis is shifted by $4 \mathrm{~h}$ to allow the model to spin up. (The low $N$ state is reached at $9 \mathrm{~h}$ in these predator-prey calculations rather than $5 \mathrm{~h}$ as in Fig. 1.) Thus, in keeping with the CRM simulations we prescribe $N(t)$, which essentially overrides the replenishment time $\tau_{2}$ and prescribes two "carrying capacity" values $N_{0}=90 \mathrm{~cm}^{-3}$ or in the low $N$ state, $N_{0}=5,15,25$, or $35 \mathrm{~cm}^{-3}$. Other system parameters are $H_{0}=650 \mathrm{~m}$ and microphysical delay $T=20 \mathrm{~min}$. The left column of Fig. 11 shows results for the
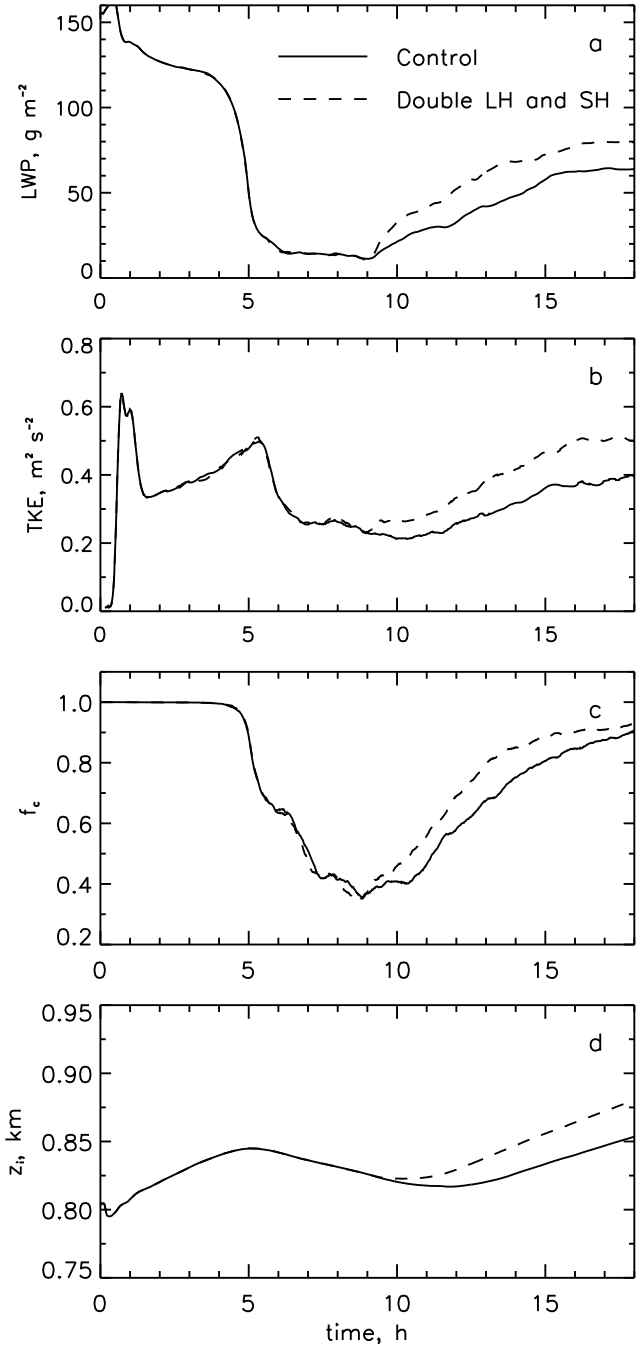

Figure 10. Simulations considering the influence of surface forcing on recovery. Solid line: control simulation; dashed line: latent and sensible heat fluxes are double their interactively calculated values after $t=9 \mathrm{~h}$, i.e., concurrent with the increase in $N$.

meteorological forcing timescale $\tau_{1}=3 \mathrm{~h}$ (Eq. 1) associated with "recharge" of liquid water (or cloud depth $H$ ). It is apparent that the larger the imposed reduction in $N$, the larger is the decrease in $H$ and the associated increase in $R$ at the onset of heavy rain, much as in Fig. 3b. Thereafter, differences in $R$ during the low $H$ period are relatively small, again in agreement with Fig. 3b. However, we do note that for the 90 to $5 \mathrm{~cm}^{-3}$ simulation, $R$ behavior is anomalous because of the overshoot to very low $H(50 \mathrm{~m})$ upon transition to very low $N$ caused by the large loss term in Eq. (1). The asymmetry in the $H$ transitions is readily apparent, with larger reductions in $N$ exhibiting stronger asymmetry much as in the CRM.

The meteorological timescale $\tau_{1}$ is now increased to $6 \mathrm{~h}$ (right column of Fig. 11), representing a slower rise to $H_{0}$, and is akin to a weaker external meteorological forcing. 

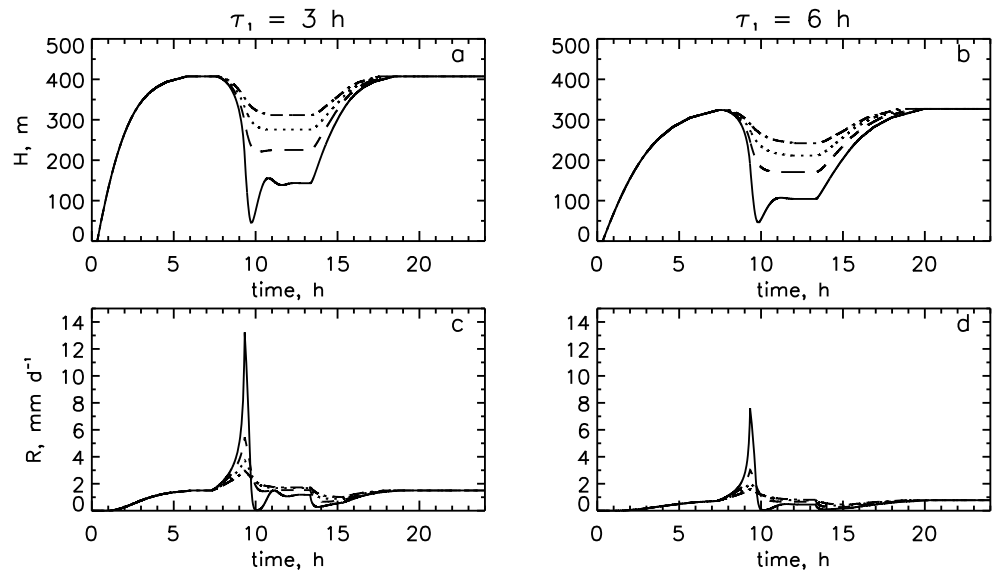

Figure 11. Predator-prey analog to the cloud system (Eqs. 1 and 3). $N(t)$ is prescribed as in Fig. 1 but the timing is $4 \mathrm{~h}$ later to allow for predator-prey model spin-up. Model parameters are $H_{0}=650 \mathrm{~m}, T=20 \mathrm{~min}$. Left column: $H$ and $R$ solutions for $H$ recovery time $\tau_{1}=3 \mathrm{~h}$; Right column: $H$ and $R$ solutions for $\tau_{1}=6 \mathrm{~h}$. Line types represent the various $N$ time series (as in Fig. 1 , but with $N$ in $\mathrm{cm}^{-3}$ ). In both cases the concurrence of rapid increase in $R$ during the rapid reduction in LWP is simulated as in Fig. 3a, b. Smaller values of $N$ perturbation exhibit faster $H$ recovery after reintroduction of $N$. Recovery is also faster in the case of smaller $\tau_{1}$.

Weaker forcing can also be achieved by decreasing $H_{0}$ itself, but this can generate values of $R$ that are unrealistic for stratocumulus and it is therefore more desirable to tune $\tau_{1}$ for these exercises. For $\tau_{1}=6 \mathrm{~h}$, the initial build-up in $H$ prior to the $N$ perturbation is slower and the rain rates are weaker. The asymmetry in the transitions is even more pronounced. This is in broad agreement with Fig. 10, where it was shown that stronger forcing (in the form of higher surface fluxes) had a significant effect on recovery.

Note that because of the existence of delay terms in Eqs. (1) and (3), one might a priori anticipate asymmetry in transitions for the imposed $N(t)$. For example, when transitioning from high $H$ and high $N$ (analogous to the closed state) to low $H$ and low $N$ (analogous to the open state), the source term for $H$ is relatively small (because $H$ is closer to $\left.H_{0}\right)$ and the loss term $\left(H^{2}(t-T) / N(t-T)\right)$ is large. This explains the very rapid closed-to-open cell transition. When transitioning from low $H$ and low $N$ to high $H$ and high $N$, the source term is relatively large but the loss term is also relatively large, particularly when the imposed $N(t-T)$ is small. This helps explain the slower recovery as well as the dependence of the recovery time on the imposed minimum value of $N$.

Finally, as with the CRM results in Fig. 9, solution to the predator-prey equations with instantaneous replenishment in $N$ also fails to produce rapid LWP recovery (figures not shown).

\subsection{Influence of radiation}

A comparison between results based on the simple radiation scheme (Stevens et al., 2005) as opposed to RRTM shows a much stronger recovery in the RRTM simulation (cf. Figs. 3a and $6 \mathrm{~b}$ ). As noted earlier, RRTM generates stronger long- wave radiative cooling than the (untuned) simple calculation, which serves to support the contention that the slow recovery is related to the delay in TKE production by cloud radiative cooling.

To explore the influence of radiation further, we consider the representation in RRTM of the effective free tropospheric air above the domain top. In the RRTM simulations thus far (Fig. 6b, c), the upper tropospheric humidity is maintained constant at the value at the domain top $\left(\approx 2 \mathrm{~g} \mathrm{~kg}^{-1}\right)$. An additional simulation in which the effective free tropospheric humidity is reduced to $0.01 \mathrm{~g} \mathrm{~kg}^{-1}$ is repeated. This would indicate a more efficient cooling of the system, e.g., in the absence of free tropospheric clouds. Note that this value only pertains to the effective radiative layer above the model top and does not directly affect the thermodynamics within the model domain. (Simulations with varying modeled free tropospheric air are shown in Fig. 6d.) As shown in Fig. 12, the more efficient cooling associated with this drier effective free troposphere generates significantly stronger turbulence and a more rapid recovery to the closed-cell state. Towards the end of the simulation this recovery of LWP is modulated to some extent by the stronger entrainment associated with the higher TKE - compounded by the solar absorption - so that LWP increases are small.

For perspective, Fig. 12 also includes comparison with the control simulation (simple long-wave radiation and standard $N$ replenishment timescale of $2 \mathrm{~h}$, with the time axis shifted so that the perturbations to $N$ coincide) and the standard RRTM simulation but with a replenishment timescale of $10 \mathrm{~h}$. We note that the rate of recovery of $N$ is clearly an important factor in recovery of the LWP and the closedcell state. Also of interest is that $z_{\mathrm{i}}$ is larger and rebounds more rapidly in the control case (simple long-wave radia- 

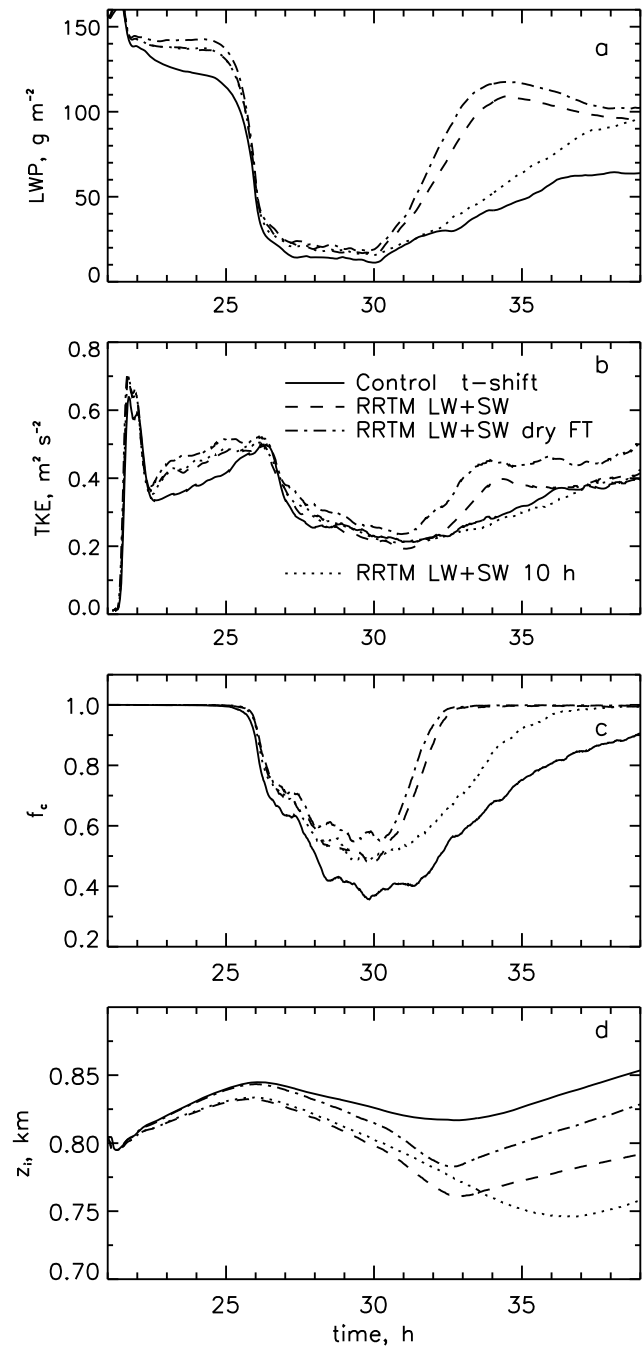

Figure 12. Perspective of different parameters controlling recovery. Solid line: control simulation with time shift such that $N(t)$ time series coincide; dashed line: RRTM simulation as in Fig. $6 \mathrm{~b}$; dotted line: same as dashed line but with $N$ recovering to $90 \mathrm{mg}^{-1}$ over $10 \mathrm{~h}$; dash-dotted line: RRTM simulation as in Fig. $6 \mathrm{~b}$ but with drier free troposphere imposed above model domain top. Minimum $N=5 \mathrm{mg}^{-1}$ in all cases. Slow replenishment of $N$ retards cloud recovery while stronger radiative forcing enhances recovery.

tion) than in the RRTM-based simulations. Closer inspection shows that for the same $N$ perturbation, the control simulation generates less surface precipitation than the RRTM simulation does (Fig. 13). The weaker thermodynamic stabilization in the control simulation allows for a deepening boundary layer. Nevertheless, the deeper boundary layer by itself is not able to sustain a deeper cloud during the recovery because the weaker radiative cooling limits the regeneration of condensate. The RRTM simulation is characterized by significantly more positive vertical velocity skewness and by stronger $q_{\mathrm{t}}$ flux. Thus while the boundary layer is on average poorly mixed, the stronger updrafts supply moisture to the top of the boundary layer, which helps to boost $f_{\mathrm{c}}$ and LWP.

The influence of absorption of solar radiation on cloud recovery (Figs. 6c and 12) is clearly manifested in both the initial stages after introduction of particles and towards the end of the simulations when LWP decreases markedly. The timing of the reintroduction of particles to the system relative to the diurnal cycle must therefore be considered to be a fundamental aspect of recovery. This point has also been raised in other modeling (Wang and Feingold, 2009b; Wang et al., 2011) and observational studies (Burleyson and Yuter, 2015).

\subsection{Influence of boundary layer depth}

The DYCOMS-II RF02 boundary layer has a tendency to deepen steadily over the course of the simulation (Fig. 5). We now consider possible influence of the boundary layer depth on open-closed cell recovery. To address this, we simulate the system described in Fig. 3 but delay the application of the perturbation in $N(t)$ until $11 \mathrm{~h}$, i.e., $8 \mathrm{~h}$ later than the standard simulation when the boundary layer is deeper. In all other respects the perturbation is the same. This result is shown as the dashed curve in Fig. 14, shifted by $t-8 \mathrm{~h}$. Clearly, recovery to the closed-cell state is very similar to that for the shallower boundary layer. However, this result cannot be generalized since boundary layer depth is one of many factors determining cloud amount. The delayed $N$ perturbation simulation generates a higher $z_{\mathrm{i}}$ throughout the simulation commensurate with the higher TKE. However, curiously LWP is lower prior to the precipitation and very close to the control simulation thereafter, so that radiative cooling is similar during the recovery stage. We have argued that recovery is closely related to the ability of the system to regenerate cloud water and radiative cooling. Why is recovery in the delayed perturbation case so similar to the control case when the same LWP has to drive circulations over a deeper boundary layer? Analysis shows that the delayed perturbation simulation produces less surface rain $R$ (both in rate and areal cover) and less thermodynamic stabilization, thus allowing the system to recover more readily (figures not shown). A more rigorous evaluation of recovery in deeper boundary layers such as those observed in the Southeast Pacific (Wood et al., 2011) is left to later study.

\subsection{Mean vs. standard deviation of LWP phase diagrams}

While the asymmetry in the closed-open-closed cell transitions shows up clearly in the LWP and TKE time series, the system also displays asymmetry in other temporal evolution aspects. Considering parameterization applications, Yamaguchi and Feingold (2015) examined the domain mean LWP $(\mu(\mathrm{LWP}))$ vs. domain standard deviation of LWP $(\sigma(\mathrm{LWP}))$ and showed that for the same case (and model) de- 

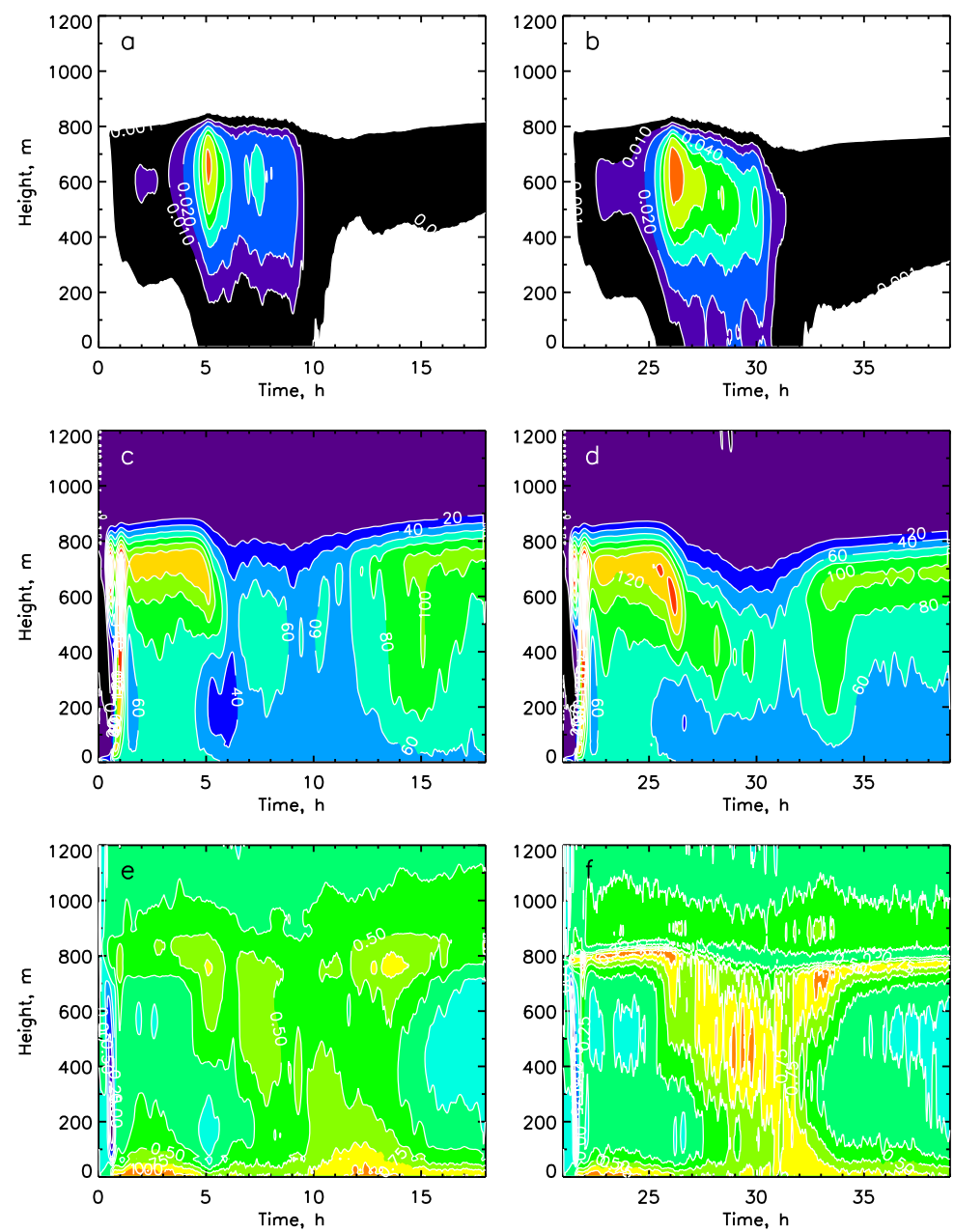

Figure 13. Domain average profiles of (a) and (b) rain water content $q_{\mathrm{r}}$, (c) and (d) $q_{\mathrm{t}}$ flux, and (e) and (f) vertical velocity skewness. Left column: control case with minimum $N=5 \mathrm{mg}^{-1}$; right column: RRTM simulation (dashed line in Fig. 12). Stronger drizzle in the RRTM simulation generates stronger positive skewness and higher $q_{\mathrm{t}}$ flux during the open-cell period, which help maintain higher $f_{\mathrm{c}}$ and LWP (Fig. 12). Contour intervals: rain water content: $0.01,0.02,0.04,0.06,0.08,0.12,0.18 \mathrm{~g} \mathrm{~kg}^{-1} ; q_{\mathrm{t}}$ flux: 20 to $160 \mathrm{~W} \mathrm{~m}{ }^{-2}$ in increments of 20; skewness: -1.5 to 1.5 in increments of 0.25 . Color scales are identical for left and right columns.

scribed here, the closed- to open-cell system follows a fairly predictable path from high $\mu$ (LWP) and low $\sigma(\mathrm{LWP})$ in the closed-cell state towards lower $\mu$ (LWP) and high $\sigma(\mathrm{LWP})$ in the open-cell state. Similar analysis is repeated here for the closed-open-closed transition for a number of different simulations with and without a diurnal solar cycle and with variations in the subsidence and free tropospheric humidity. One illustrative example associated with Fig. 7 is shown in Fig. 15 but all exhibit similar features. First, the simulations all show similar phase paths as in Yamaguchi and Feingold (2015) for the closed-open transition. Of note is that for a given $\mu$ (LWP) the open-closed transition is characterized in all cases by higher $\sigma$ (LWP) than for the closed-open transition. The higher $\sigma$ (LWP) on the open-closed path is an expression of the slow recovery; i.e., the low cloudiness (high variance) state attempting to achieve a more cloudy (lower variance) state (see also Fig. 2).

\section{Summary}

This work is motivated by the radiative impacts of the large difference in the amount of solar radiation absorbed at the Earth's surface in open vs. closed cellular convection and a desire to (i) understand the propensity of cellular systems to transition back and forth between states and (ii) elucidate key processes controlling the transitions. Satellite imagery often shows ship track effluent closing open cells, and yet cloudresolving models that include different levels of complexity in the representation of the aerosol life cycle produce more ambiguous results regarding the ability of aerosol perturbations to fill in open cells (Wang and Feingold, 2009b; Wang 

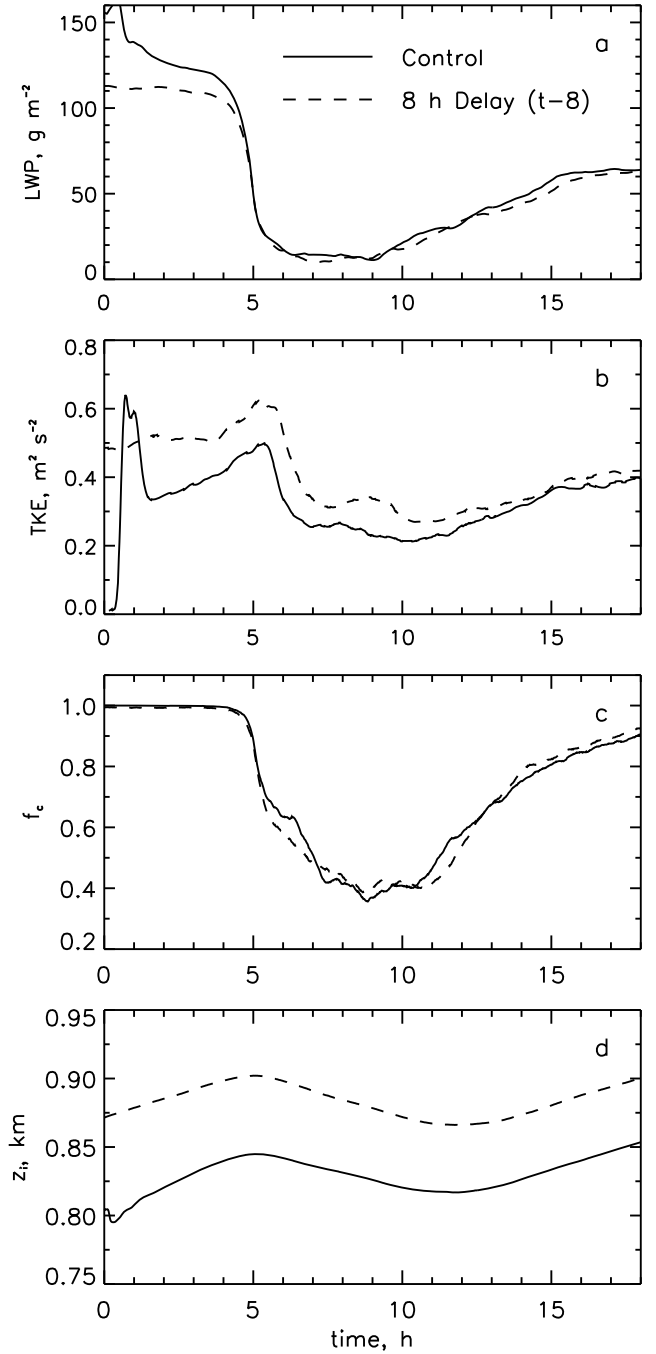

Figure 14. Investigation of importance of timing of $N$ perturbation. Solid line: control case; dashed line: control case but with $N$ perturbation delayed by $8 \mathrm{~h}$ during which time the boundary layer has deepened (time axis shifted so $N$ perturbation coincides). In both cases LWP and $f_{\mathrm{c}}$ recovery are similar.

et al., 2011; Berner et al., 2013). Rather than include detailed representation of aerosol processes as in Kazil et al. (2014), we have elected to prescribe a simple symmetrical time series of the drop concentration evolution $N(t)$. Even this symmetrical $N(t)$ does not produce a symmetrical LWP $(t)$, suggesting that some underlying system behavior is responsible for the relatively slow recovery. The key results of this study can be recapitulated as follows.

1. In stratocumulus clouds driven by cloud-top radiative cooling, changes in LWP precede changes in TKE. Once in the open-cell state, the recovery of the system depends on regeneration of LWP and attendant radiative cooling; thus the lag in TKE build-up represents a barrier to recovery. Although injection of aerosol into the

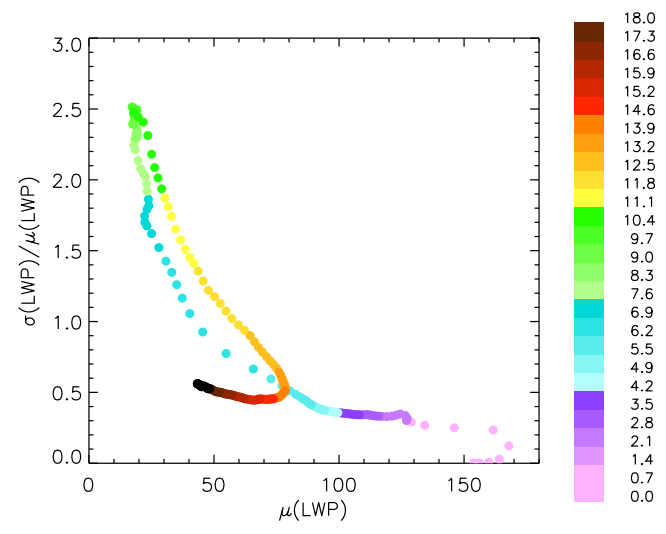

Figure 15. Phase diagram for the relative dispersion of $\operatorname{LWP}(\sigma(\mathrm{LWP}) / \mu(\mathrm{LWP}))$ vs. the mean $\operatorname{LWP}(\mu(\mathrm{LWP}))$ for the simulation in Fig. 7. Colors indicate simulation time. Note that the recovery from open- to closed-cell state is characterized by higher $\sigma / \mu$ for given $\mu$.

system helps suppress precipitation and generate LWP, until $N$ is large enough, the increasing LWP also helps generate precipitation, representing further barrier to recovery. Thus while a recharge of $N$ is a necessary condition for recovery from the open-cell state, it cannot explain the basic asymmetry in the recovery.

2. The relatively slow open-closed transition is related to the stabilization caused by the rain during the low $N$ open-cell state and the relatively long time it takes for a build-up in the TKE after the reintroduction of $N$. The recovery is slower when long-wave cooling is countered by shortwave absorption (Fig. 6c), for large imposed reductions in $N$ (Figs. 3, 4, 6), and when the rate of reintroduction of $N$ is slow (Fig. 12) or the amount too small (Wang et al., 2011). Cloud layers within the free troposphere would also reduce the effectiveness of long-wave cooling and delay recovery (Fig. 12).

3. A region of sub-cloud buoyancy consumption of TKE during the recovery from open-to-closed cells has been identified (Fig. 8b). Examination of a sample of the simulations presented herein show that the extent, magnitude, and persistence of this area is proportional to the amount of rain generated during the open-cell phase. Recovery to the closed-cell state proceeds once this barrier has been removed and surface moisture can be transported more effectively to the cloud (Fig. 8c). For example, recovery is more rapid when stronger surface latent and sensible heat fluxes are coincident with the replenishment of $N$ (Fig. 10). In this case, the region of buoyancy consumption of TKE is significantly reduced and surface vapor can reach the cloud layer more readily. 
4. In the predator-prey model, asymmetry is a fundamental property of the equations because they include delay terms. It is shown that the degree of the asymmetry is controlled by the timescale for replenishment of $H$, i.e., $\tau_{1}$ (or alternatively $H_{0}$; Eq. 1 ) after recovery from the open-cell state. Simple tests with either small $\tau_{1}$ or large $H_{0}$, i.e., strong meteorological forcing accompanying the injection of aerosol, result in more symmetric transitions.
These results shed light on why the transition from open to closed cellular state can be significantly more difficult than the reverse and point to the need to understand the meteorological, radiative, and surface flux environment in which these transitions occur. Transitions from the open to the closed cellular state are expected to be slower during the daytime, when the free troposphere is cloudier (Fig. 12), and when aerosol perturbation/replenishment is slow (Fig. 12). Aspects of this hypothesis can be tested with satellite observations and reanalysis. 


\section{Appendix A: Sensitivity to grid spacing}

The standard simulations are all performed on a relatively coarse grid spacing of $\Delta x \times \Delta y \times$ $\Delta z=200 \mathrm{~m} \times 200 \mathrm{~m} \times 10 \mathrm{~m}$ (aspect ratio of $20: 1$ ). Before embarking on the more extensive simulations presented here, system response was explored for finer grids and smaller aspect ratios: $\Delta x \times \Delta y \times \Delta z=100 \mathrm{~m} \times 100 \mathrm{~m} \times 10 \mathrm{~m}$ (aspect ratio of 10:1) and $75 \mathrm{~m} \times 75 \mathrm{~m} \times 10 \mathrm{~m}$ (aspect ratio of $7.5: 1)$. All simulations were performed on the same domain size $(40 \mathrm{~km})$. Figure A1 compares the LWP, TKE, $f_{\mathrm{c}}$, and $z_{\mathrm{i}}$ time series for these three configurations and shows that the characteristic behavior of these simulations is similar. The finer grid simulations tend to generate more vigorous and deeper boundary layers. Rates of recovery of LWP and $f_{c}$ are similar. While it would be desirable perhaps to perform all simulations at higher resolution and smaller aspect ratios, Fig. A1 suggests that the key aspects of the system response are robust to grid spacing.
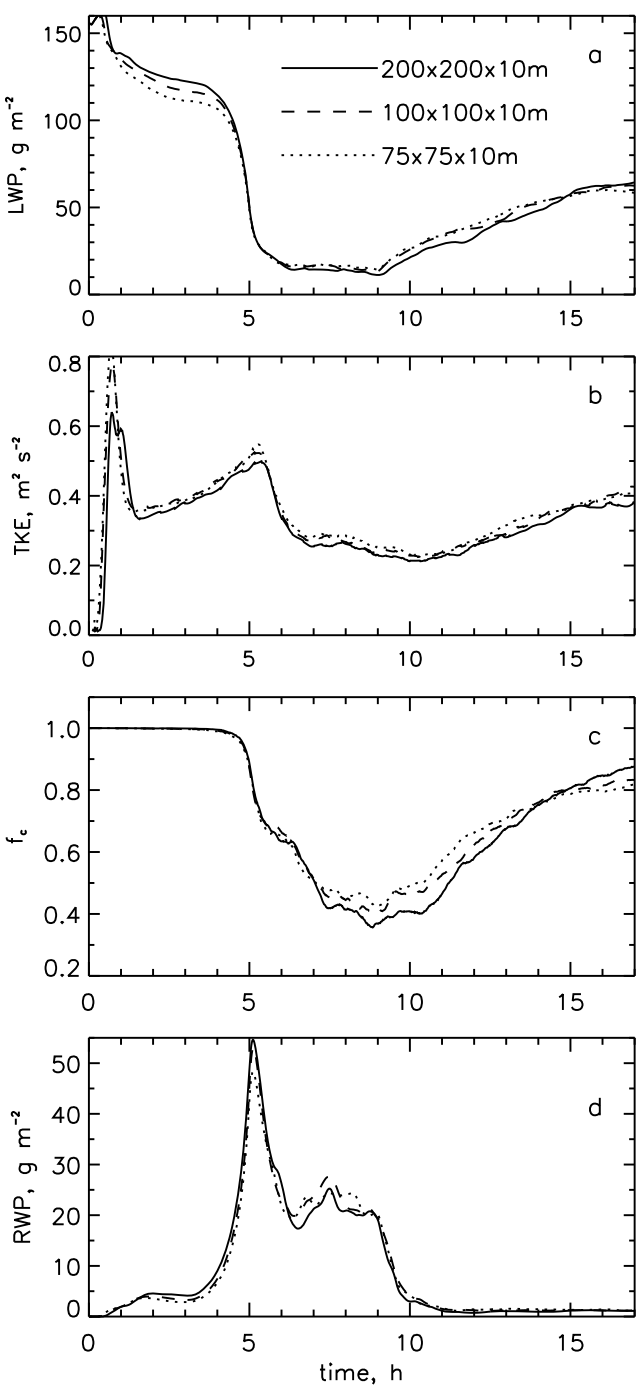

Figure A1. Sensitivity of results to grid spacing (meters). 
Acknowledgements. G. Feingold, T. Yamaguchi, and J. Kazil are funded by NOAA's Climate Goal and the Department of Energy's Atmospheric Science Program. I. Koren is funded by the European Research Council under the European Union's Seventh Framework Programme (FP7/2007-2013)/ERC grant agreement number [306965]. The authors are most grateful to Marat Khairoutdinov for sharing his System for Atmospheric Modeling and to P. Blossey for his help with the RRTM code integration.

Edited by: H. Su

\section{References}

Ackerman, A. S., vanZanten, M. C., Stevens, B., Savic-Jovcic, V., Bretherton, C. S., Chlond, A., Golaz, J.-C., Jiang, H., Khairoutdinov, M., Krueger, S. K., Lewellen, D. C., Lock, A., Moeng, C.-H., Nakamura, K., Petters, M. D., Snider, J. R., Weinbrecht, S., and Zulauf, M.: Large-eddy simulations of a drizzling, stratocumulus-topped marine boundary layer, Mon. Weather. Rev., 137, 1083-1110, 2009.

Berner, A. H., Bretherton, C. S., Wood, R., and Muhlbauer, A.: Marine boundary layer cloud regimes and POC formation in a CRM coupled to a bulk aerosol scheme, Atmos. Chem. Phys., 13, 12549-12572, doi:10.5194/acp-13-12549-2013, 2013.

Burleyson, C. D. and Yuter, S. E.: Subdiurnal stratocumulus cloud fraction variability and sensitivity to precipitation, J. Climate, 28, 2968-2985, doi:10.1175/JCLI-D-14-00648.1, 2015.

Cavallo, S. M., Dudhia, J., and Snyder, C.: A multilayer upperboundarycondition for longwave radiative flux to correct temperature biases in a mesoscale model, Mon. Weather Rev., 139, 1952-1959, 2010.

Feingold, G. and Koren, I.: A model of coupled oscillators applied to the aerosol-cloud-precipitation system, Nonlin. Processes Geophys., 20, 1011-1021, doi:10.5194/npg-20-10112013, 2013.

Feingold, G., Kreidenweis, S. M., Stevens, B., and Cotton, W. R.: Numerical simulation of stratocumulus processing of cloud condensation nuclei through collision-coalescence, J. Geophys. Res., 101, 21391-21402, 1996.

Feingold, G., Koren, I., Wang, H., Xue, H., and Brewer, W. A.: Precipitation-generated oscillations in open cellular cloud fields, Nature, 466, 849-852, doi:10.1038/nature09314, 2010.

Goren, T. and Rosenfeld, D.: Satellite observations of ship emission induced transitions from broken to closed cell marine stratocumulus over large areas, J. Geophys. Res., 117, D17206, doi:10.1029/2012JD017981, 2012.

Jiang, Q. and Wang, S.: Aerosol Replenishment and Cloud Morphology: A VOCALS Example, J. Atmos. Sci., 71, 300-311, doi:10.1175/JAS-D-13-0128.1, 2014.

Kazil, J., Wang, H., Feingold, G., Clarke, A. D., Snider, J. R., and Bandy, A. R.: Modeling chemical and aerosol processes in the transition from closed to open cells during VOCALS-REx, Atmos. Chem. Phys., 11, 7491-7514, doi:10.5194/acp-11-74912011, 2011.

Kazil, J., Feingold, G., Wang, H., and Yamaguchi, T.: On the interaction between marine boundary layer cellular cloudiness and surface heat fluxes, Atmos. Chem. Phys., 14, 61-79, doi:10.5194/acp-14-61-2014, 2014.
Khairoutdinov, M. F. and Kogan, Y. L.: A new cloud physics parameterization in a large-eddy simulation model of marine stratocumulus, Mon. Weather Rev., 128, 229-243, 2000.

Khairoutdinov, M. F. and Randall, D. A.: Cloud resolving modeling of the ARM summer 1997 IOP: model formulation, results, uncertainties, and sensitivities, J. Atmos. Sci., 60, 607-625, 2003.

Koren, I. and Feingold, G.: The aerosol-cloud-precipitation system as a predator-prey problem, P. Natl. Acad. Sci., 108, 1222712232, doi:10.1073/pnas.1101777108, 2011.

Koren, I. and Feingold, G.: Adaptive behavior of marine cellular clouds, Nature Sci. Rep., 3, 2507, doi:10.1038/srep02507, 2013.

Larson, V. E., Kotenberg, K. E., and Wood, N. B.: An Analytic Longwave Radiation Formula for Liquid Layer Clouds, Mon. Weather Rev., 135, 689-699, doi:10.1175/MWR3315.1, 2007.

Mechem, D. B., Yuter, S. E., and De Szoeke, S. P.: Thermodynamic and aerosol controls in southeast Pacific stratocumulus, J. Atmos. Sci., 69, 1250-1266, 2012.

Mlawer, E. J., Taubman, S. J., Brown, P. D., Iacono, M. J., and Clough, S. A.: Radiative transfer for inhomogeneous atmospheres: RRTM, a validated correlated-k model for the longwave, J. Geophys. Res., 102, 16663-16682, 1997.

Moeng, C.-H.: Large eddy simulation of a stratus-topped boundary layer. Part II. Implications for mixed layer modeling, J. Atmos. Sci., 44, 1605-1614, 1987.

Pawlowska, H. and Brenguier, J. L.: An observational study of drizzle formation in stratocumulus clouds for general circulation model (GCM) parameterizations, J. Geophys. Res., 108, 8630, doi:10.1029/2002JD002679, 2003.

Savic-Jovcic, V. and Stevens, B.: The structure and mesoscale organization of precipitating stratocumulus, J. Atmos. Sci., 65, 15871605, 2008.

Sharon, T. M., Albrecht, B. A., Jonsson, H. H., Minnis, P., Khaiyer, M. M., van Reken, T. M., Seinfeld, J., and Flagan, R.: Aerosol and cloud microphysical characteristics of rifts and gradients in maritime stratocumulus clouds, J. Atmos. Sci., 63, 983-997, 2006.

Stevens, B., Cotton, W. R., Feingold, G., and Moeng, C.H.: Large-eddy simulations of strongly precipitating, shallow, stratocumulus-topped boundary layers, J. Atmos. Sci., 55, 36163638, 1998.

Stevens, B., Vali, G., Comstock, K., Wood, R., Van Zanten, M. C., Austin, P. H., Bretherton, C. S., and Lenschow, D. H.: Pockets of open cells and drizzle in marine stratocumulus, B. Am. Meteorol. Soc., 86, 51-57, 2005.

Wang, H. and Feingold, G.: Modeling mesoscale cellular structures and drizzle in marine stratocumulus. Part I: Impact of drizzle on the formation and evolution of open cells, J. Atmos. Sci., 66, 3237-3256, 2009a.

Wang, H. and Feingold, G.: Modeling mesoscale cellular structure and drizzle in marine stratocumulus. Part II: The microphysics and dynamics of the boundary region between open and closed cells, J. Atmos. Sci., 66, 3257-3275, 2009b.

Wang, H., Rasch, P. J., and Feingold, G.: Manipulating marine stratocumulus cloud amount and albedo: a process-modelling study of aerosol-cloud-precipitation interactions in response to injection of cloud condensation nuclei, Atmos. Chem. Phys., 11, 4237-4249, doi:10.5194/acp-11-4237-2011, 2011. 
Wood, R. and Hartmann D. L.: Spatial variability of liquid water path in marine low cloud: The importance of mesoscale cellular convection, J. Climate, 19, 1748-1764, 2006.

Wood, R., Mechoso, C. R., Bretherton, C. S., Weller, R. A., Huebert, B., Straneo, F., Albrecht, B. A., Coe, H., Allen, G., Vaughan, G., Daum, P., Fairall, C., Chand, D., Gallardo Klenner, L., Garreaud, R., Grados, C., Covert, D. S., Bates, T. S., Krejci, R., Russell, L. M., de Szoeke, S., Brewer, A., Yuter, S. E., Springston, S. R., Chaigneau, A., Toniazzo, T., Minnis, P., Palikonda, R., Abel, S. J., Brown, W. O. J., Williams, S., Fochesatto, J., Brioude, J., and Bower, K. N.: The VAMOS Ocean-Cloud-AtmosphereLand Study Regional Experiment (VOCALS-REx): goals, platforms, and field operations, Atmos. Chem. Phys., 11, 627-654, doi:10.5194/acp-11-627-2011, 2011.
Xue, H. and Feingold, G.: Large eddy simulations of trade-wind cumuli: Investigation of aerosol indirect effects, J. Atmos. Sci., 63, 1605-1622, 2006.

Xue, H., Feingold, G., and Stevens, B.: Aerosol effects on clouds, precipitation, and the organization of shallow cumulus convection, J. Atmos. Sci., 65, 392-406, 2008.

Yamaguchi, T. and Feingold, G.: On the relationship between open cellular convective cloud patterns and the spatial distribution of precipitation, Atmos. Chem. Phys., 15, 1237-1251, doi:10.5194/acp-15-1237-2015, 2015.

Yamaguchi, T., Randall, D. A., and Khairoutdinov, M. F.: Cloud modeling tests of the ULTIMATE-MACHO scalar advection scheme, Mon. Weather Rev., 139, 3248-3264, 2011. 